\title{
Vascular Tissue-Specific Expression of Bnac4.BOR1;1C, an Efflux Boron Transporter Gene, is Regulated in Response to Boron Availability for Efficient Boron Acquisition in Brassica Napus
}

\section{Sheliang Wang}

Huazhong Agricultural University

Ling Liu

Huazhong Agricultural University

Dan Zou

Huazhong Agricultural University

Yupu Huang

Huazhong Agricultural University

Zhe Zhao

Huazhong Agricultural University

Guangda Ding

Huazhong Agricultural University

Hongmei Cai

Huazhong Agricultural University

Chuang Wang

Huazhong Agricultural University

Lei Shi

Huazhong Agricultural University

Fangsen Xu ( $\nabla$ fangsenxu@mail.hzau.edu.cn )

Huazhong Agricultural University https://orcid.org/0000-0003-3564-1644

\section{Research Article}

Keywords: Brassica napus, BnaC4.BOR1;1c, boron response, boron acquisition

Posted Date: April 6th, 2021

DOl: https://doi.org/10.21203/rs.3.rs-385679/v1

License: (c) (1) This work is licensed under a Creative Commons Attribution 4.0 International License.

Read Full License 
Page $2 / 23$ 


\section{Abstract}

Aims

BnaC4.BOR1;1c is required for B acquisition in Brassica napus (B. napus) under low B stress. This study

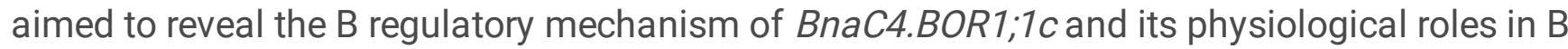
translocation from roots to shoots and B distribution in shoots.

Methods

Transgenic Arabidopsis plants expressing GUS ( $\beta$-glucuronidase) under different promoters were generated and the mRNA, and GUS activity was quantitatively measured. The in-situ PCR and immunohistochemistry in $B$. napus were performed to investigate BnaC4.BOR $1 ; 1$ c expression pattern and localization. Furthermore, assays of $B$ transport and distribution in wild type $B$. napus and BnaC4.BOR1;1c RNAi lines were carried out to elucidate its physiological roles.

Results

Results showed that BnaC4.BOR1;1c mRNA abundance is negatively correlated with B availability, which was mediated by the 29 nt sequence in the $5^{\prime}$ terminal region of 5'-UTR. Besides, the $5^{\prime}$-UTR simultaneously regulates protein expression level, most probably depending on the translation efficiency. BnaC4.BOR1;1c mainly localizes on the plasma membrane of vascular bundle cells in roots and shoots with a polar localization manner that is probably beneficial to B xylem loading in roots and B unloading from xylem to phloem in vascular bundle of shoots. Short-term ${ }^{10} \mathrm{~B}$ uptake analysis demonstrates that BnaC4.BOR1;1c preferentially distributes B to developing leaves and flowers under B deficiency.

\section{Conclusion}

This study reveals combined regulatory action of mRNA abundance and translation efficiency mediated by the $5^{\prime}$-UTR in BnaC4.BOR1;1c in response to B availability and its physiological role in preferential $\mathrm{B}$ acquisition in developing tissues of $B$. napus.

\section{Introduction}

Boron (B) is one of the essential micronutrients for plant growth, but B excess is toxic. B plays an essential structural role in maintaining the cell wall integrity by crosslinking two rhamnogalacturonan II (RG-II) molecules to form RG-II-B complexes (O'Neill et al., 2001; Funakawa and Miwa, 2015). B is relatively immobile in plant cells; thus, B deficiency defects are early occurred in the developing tissues, such as necrosis and elongation cessation of the root tip, curl and reduced expansion of young leaves, and low fertility (Broadley et al., 2012; Zhang et al., 2017). Boron deficiency is a worldwide agricultural problem. The continuous $B$ acquisition of plants from the environment mainly depends on two type $B$ transporters. AtNIP5;1 (nodulin 26-like intrinsic protein 5;1) was identified as a boric acid influx transporter, and AtNIP5;1 protein mainly localizes on the plasma membrane (PM) toward the soil-side in 
the outmost cell layer and endodermis of a root tip in Arabidopsis (Takano et al., 2006, 2010). Loss of AtNIP5; 1 function significantly reduces root B uptake capacity (Takano et al., 2006). AtBOR1 functions as a boric acid/borate exporter on the PM of root epidermis and endodermis although expression in the cotyledon tip also reported (Takano et al., 2002; Yoshinari et al., 2016). In contrast to AtNIP5;1, AtBOR1 localizes on the PM toward the stele-side (Takano et al., 2010). Furthermore, many homologs of Arabidopsis NIP5;1 and BOR1 have been functionally characterized in succession in various species such as rice (Nakagawa et al., 2007; Hanaoka et al., 2014; Shao et al., 2021), barley (Sutton et al., 2007), wheat (Leaungthitikanchana et al., 2013), maize (Chatterjee et al., 2014; Durbak et al., 2014; Leonard et al., 2014) and oilseed rape (Zhang et al., 2017).

Efficient acquisition and avoiding $B$ toxicity need a fine-tuning of the B homeostasis due to the narrow window of physiological B concentration between deficiency and toxicity (Warington, 1923; Nable et al., 1997). B concentration in vivo is negatively correlated with AtNIP5;1 mRNA abundance in Arabidopsis through an AUG-stop element-mediated mRNA degradation procedure (Tanaka et al., 2011, 2016). In barley, reduced mRNA abundance of $H V N I P 2 ; 1$ restricts $B$ uptake leading to B toxicity tolerance in plants (Schnurbusch et al., 2010). The distinct B-dependent regulatory mechanisms are found in the AtBOR1 gene expression regulation (Takano et al., 2010; Aibara et al., 2018). Protein translation efficiency of AtBOR1 is inhibited upon the $5^{\prime}-\mathrm{UTR}$, and its protein suffers degradation in the vacuole under high $\mathrm{B}$ stress (Kasai et al., 2011; Takano et al., 2010; Aibara et al., 2018). Besides, overexpression of AtBOR4 (paralog of $A t B O R 1$ ) can exclude B from the root resulting in enhanced tolerance to B toxicity (Miwa et al., 2007). A similar role of Bot1 (AtBOR1 homolog) in barley was characterized, and a high copy number of Bot1 increases barley tolerance to B toxicity (Reid 2007; Sutton et al., 2007).

Developing tissue with low transpiration preferentially acquires B from xylem sap in many plants suggesting that B transporter might contribute to B translocation (Marentes et al., 1997; Huang et al., 2001; Takano et al., 2001; Matoh and Ochiai, 2005;). To date, AtNIP6;1 and AtNIP7;1 were functionally characterized to facilitate B acquisition in young leaves and flowers (Tanaka et al., 2008; Li et al., 2011; Routray et al., 2018). In rice, OsNIP3;1 acts as a boric acid channel and preferentially distributes $B$ to the developing tissues by unloading B from the xylem in nodes (Hanaoka et al., 2014; Shao et al., 2017). Besides, mineral element distribution in shoot tissues mediated by their transporters in the nodes has been well established in rice (Yamaji and Ma, 2014; 2017). However, little is known about the exact role of members of the BORs family in distributing $B$ in shoots. We previously identified a boric acid/borate transporter gene BnaC4.BOR1;1C in Brassica napus (B. napus) with low B inducible expression pattern (Sun et al., 2012). BnaC4.BOR1;1 c localizes in the stele of root, nodes in shoots, and base of the floral organ (Zhang et al., 2017). RNA interference of BnaC4.BOR1;1C significantly reduced B concentrations in shoots and flowers accompanied by the B defective phenotype of $B$. napus (Zhang et al., 2017), probably due to the reduced $B$ xylem loading in roots. However, the B-dependent regulatory mechanism of BnaC4.BOR1;1c and its physiological role in B distribution in shoot tissues remains unclear. Here, we found that $B$ not only regulates mRNA abundance but also adjusts BnaC4.BOR1;1c protein level in a 5'UTR-dependent manner. Furthermore, tracer B experiments indicate that BnaC4.BOR1;1c plays a vital role 
in preferentially distributing $B$ from xylem to phloem in nodes for developing tissue growth under $B$ deficiency.

\section{Results}

\section{The $5^{\prime}$-UTR is required for the B-dependent regulation of BnaC4.BOR1;1C}

It has been reported that low B upregulates BnaC4.BOR1;1c expression in a B-efficient B. napus CV. 'QY10' (Sun et al., 2012). To investigate the mechanism of B-dependent mRNA regulation, the mRNA abundance in $B$. napus root was quantified by quantitative real-time PCR (qRT-PCR) in the presence of low $B(0.25$ $\mu \mathrm{M})$, medium B $(25 \mu \mathrm{M})$, and high B $(250 \mu \mathrm{M})$. Low B enhanced BnaC4.BOR1;1c expression relative to medium $B$ condition, while high $B$ significantly inhibited mRNA accumulation compared to medium $B$ condition (Fig. 1a). This regulation pattern of BnaC4.BOR1;1 C by B supply is similar to the B-dependent mRNA regulatory mechanism of NIP5;1 in Arabidopsis (Tanaka et al., 2011, 2016). The 5'-UTR sequence of BnaC4.BOR1;1c was identified experimentally (Sun et al., 2012). We, therefore, generated transgenic Arabidopsis carrying the ProBOR1;1C (5'-UTR): GUS and 5'-UTR-deleted ProBOR1;1C ( $\Delta 5^{\prime}$-UTR): GUS to evaluate their effects on the expression abundance (Fig. 1b). The relative expression level of GUS in plants grown on $0.25 \mu \mathrm{M}$ B or $250 \mu \mathrm{M}$ B was determined. High B treatment accumulated lower GUS mRNA abundance relative to low $B$ treatment in plants carrying ProBOR1;1C (5'-UTR): GUS construct (Fig. 1C). Construct with deletion of $5^{\prime}$-UTR was almost entirely insensitive to $B$ regulation (Fig. 1c). These results demonstrate that 5'-UTR of BnaC4.BOR1;1 $c$ is required for the B-dependent mRNA abundance regulation.

\section{$5^{\prime}$ terminal region of $5^{\prime}-U_{T R}$ contributes to the B-dependent regulation of BnaC4.BOR1;1C}

The 5'-UTR sequence of BnaC4.BOR1;1 c consists of $351 \mathrm{nt}$ upstream of its main open reading frame (ORF), in which two mini uORFs (Fig. 2a) and three more uORFs existed (Figure S1). Considering the important role of mini uORF and its upstream sequence in B-dependent mRNA regulation (Tanaka et al., 2011, 2016), the constructs of Pro35S (5'-UTR): GUS, Pro35S (5'-UTR $\Delta^{1-29}$ ): GUS and Pro35S (5'-UTR $\Delta^{1-}$

${ }^{97}$ ): GUS were generated to investigate the B response in Arabidopsis plants (Fig. 2). The $29 \mathrm{nt}$ region and $97 \mathrm{nt}$ region in the $5^{\prime}$ terminal region includes the first AUG-stop and second AUG-stop, respectively

(Fig. 2a and Figure S1). Either 1-29 nt deletion or 1-97 nt deletion from the $5^{\prime}$ terminal region in the 5'UTR completely abolished the high B effect on the mRNA (Fig. 2c), suggesting that the $29 \mathrm{nt}$ sequence in the $5^{\prime}$ terminal region of $5^{\prime}$-UTR is required for the high $B$ response. We further validated this conclusion that deletion of 92-97 nt (corresponding to second AUG-stop, Fig. 2a) in the 5'-UTR maintained a rapid high $B$ response (Fig. 2C). Consistent with this, both 1-29 nt deletion and 1-97 nt deletion significantly reduced the high $B$ inhibition of GUS activity relative to low B condition, and the relative GUS activity of deletion of the 92-97 nt in the 5'-UTR remained lower level at high B condition (Figure S2). Interestingly, compared with low B condition, the GUS activities of Pro35S.(5'- UTR $\Delta^{1-29}$ ): GUS and Pro35S.(5'-UTR $\Delta^{1-}$ ${ }^{97}$ ): GUS were partially reduced at high B condition (Figure S2), though their mRNA levels were 
comparable at both low $B$ and high $B$ conditions (Fig. 2c). Taken together, these results suggest that the $5^{\prime}$ terminal 1-29 nt region in the 5'-UTR contributes to the B-dependent regulation of BnaC4.BOR1;1C.

\section{Localization of BnaC4.BOR1;1c in B. napus}

Undoubtedly, the total reduced B content in the shoots of BnaC4.BOR1;1c RNAi plants can be ascribed to the down translocation of $B$ in the roots of BnaC4.BOR1;1C (Zhang et al., 2017). Although BnaC4.BOR1;1C promoter activity has been observed in the root stele, node, and base of the floral organ in proBnaC4.BOR1;1C: GUS transgenic Arabidopsis (Zhang et al., 2017), the details of BnaC4.BOR1;1C localization in these tissues of $B$. napus is not clarified. To this end, we first performed the in-situ PCR (Athman et al., 2014) of BnaC4.BOR1;1C in the root, hypocotyl, and node of B. napus. For the negative control, no BnaC4.BOR1;1C reverse primer was used in the reverse transcription PCR. Compared with negative control (Fig. 3a), a strong signal was detected in the cells surrounding the stele of root (Fig. 3b). In the hypocotyl, the signal mainly existed in the vascular tissues (Fig. 3d, e), while no detectable signal was showed in the negative control (Fig. 3c). Then the localization of BnaC4.BOR1;1 c mRNA in the nodes was investigated. The vascular bundles showed clear signals (Fig. 3f), including the xylem, cambium (Fig. 3h), and indeed no specific signal was detected in these cells of negative control (Fig. $3 \mathrm{~g}$ ).

In parallel, we performed immunohistochemistry staining of the roots and nodes of $B$. napus using an antibody that was generated against an artificial peptide of the BnaC4.BOR1;1c region (SSTPLNNRSLSSPR). The plants 'QY10' and RNAi plants grown on $0.25 \mu \mathrm{M}$ B were sampled for the positive and negative control, respectively. The strong green signal was imaged on the PM of cells surrounding stele in 'QY' roots (Fig. 4a, b) compared to the RNAi plants (Fig. 4c, d). In line with the polar localization of AtBOR1 on the PM of root cells toward the stele-side (Takano et al., 2010), the polar localization toward the stele-side was observed in B. napus (Fig. 4a, b). In the nodes of B. napus, the signal was mainly detected in the xylem and cambium of vascular bundles (Fig. 4e-h). Polar localization on the cambium cell toward to phloem was observed. Furthermore, $250 \mu \mathrm{M} \mathrm{B}$ is sufficient to abolish BnaC4.BOR1;1c protein accumulation in roots and nodes (Fig. 4i-I). Because the artificial peptide of BnaC4.BOR1;1c was partially conserved among BnaBOR1s (Figure S3), the results presumably represent the localization of multiple BnaBOR1 proteins in B. napus. To clarify the localization of BnaC4.BOR1;1C, transgenic Arabidopsis expressing BnaC4.BOR1;1c-GFP was generated. Polar localization of BnaC4.BOR1;1C-GFP toward stele-side on the PM of both epidermis and endodermis was observed in Arabidopsis (Fig. 4m-o). Taken together, these results demonstrate that BnaC4.BOR1;1 c is polarly localized on the PM of cells in vascular tissues.

\section{BnaC4.BOR1;1c transports B in yeast and in B. napus}

Despite the symptoms of B deficiency were observed in BnaC4.BOR1;1c RNAi B. napus (Zhang et al., 2017), the transport activity of BnaC4.BOR1;1C is not validated in the plant. Previously, the $B$ transport activity of BnaC4.BOR1;1c in yeast was reported (Diehn et al., 2019), while yeast expressing BnaC4.BOR1;1C did not show stronger growth than that of yeast expressing empty vector on the high $B$ medium (Diehn et al., 2019). To clarify the B transport activity of BnaC4.BOR1;1c, yeast Scbor1 mutant 
was employed to express target genes. AtBOR1 was used as a positive control because its B transport activity had been demonstrated (Takano et al., 2002). In agreement with the result (Diehn et al., 2019), the yeasts with induction of pYES2, AtBOR1, and BnaC4.BOR1;1c did not show distinct growth inhibition on the medium without $B$, while the best growth was observed for the AtBOR1-yeast, then followed by BnaC4.BOR1;1c-yeast, and the pYES2-yeast at the $20 \mathrm{mM} \mathrm{B}$ medium (Figure S4). The similar growth between pYES2-yeast and BnaC4.BOR1;1c yeast cannot strongly demonstrate that BnaC4.BOR1;1 c can export $B$ from yeast cells. Thus, we further compared the intracellular $B$ concentrations among these yeasts. Yeasts were incubated in $500 \mu \mathrm{M} \mathrm{B}$ for $60 \mathrm{~min}$ in galactose medium, the pYES2-yeast had about $1.1 \mathrm{mmol} \mathrm{B} / \mathrm{kg} \mathrm{DW}$, while both AtBOR1-yeast and BnaC4.BOR1;1-yeast had lower B concentrations ( $0.34 \mathrm{mmol} \mathrm{B} / \mathrm{kg} \mathrm{DW}$ and $\sim 0.52 \mathrm{mmol} \mathrm{B} / \mathrm{kg} \mathrm{DW}$ ) (Fig. 5a). This result demonstrated that BnaC4.BOR1;1c has $B$ transport activity. The $B$ transport activity of BnaC4.BOR1;1 $\mathrm{c}$ was further investigated in $B$. napus using the RNAi lines for B's transient uptake assay (Zhang et al., 2017). Plants grown hydroponically with $100 \mu \mathrm{M}^{11} \mathrm{~B}$ were transferred to $0.25 \mu \mathrm{M}^{11} \mathrm{~B}$ for $24 \mathrm{~h}$, then $5 \mu \mathrm{M}{ }^{10} \mathrm{~B}$ for $24 \mathrm{~h}$, and the ${ }^{10} \mathrm{~B}$ concentrations in roots and shoots were measured by inductively coupled plasma-mass spectrometry (ICP-MS). The amount of ${ }^{10} \mathrm{~B}$ transported into shoots per unit dry weight of roots within $24 \mathrm{~h}$ was defined as the BnaC4.BOR1;1c function in roots. The RNAi lines showed lower ${ }^{10} \mathrm{~B}$ accumulation in shoots than wildtype 'QY10' (Fig. 5b), indicating that BnaC4.BOR1;1c can facilitate B translocation from roots into shoots.

\section{BnaC4.BOR1;1c contributes to preferential B acquisition of developing tissues under B deficiency}

To investigate whether BnaC4.BOR1;1c contributes to B acquisition in developing tissues in shoots such as flower and young leaves; labeling experiments were performed using the isotope $B$. The top inflorescence of wild-type 'QY10' and BnaC4.BOR1;1C RNAi lines grown in ${ }^{11} \mathrm{~B}$-enriched solution (100 $\left.\mu \mathrm{M}\right)$ were incubated in $5 \mu \mathrm{M}{ }^{10} \mathrm{~B}$-enriched solution for two days. ICP-MS measurement of ${ }^{10} \mathrm{~B}$ concentration showed that wild-type buds had higher $B$ concentrations than RNAi buds (Fig. 6a). This result indicates that BnaC4.BOR1;1 c contributes to $B$ acquisition of buds. $B$ is usually immobile in most plant species (Brown and Shelp, 1997). We tested the B mobility in B. napus and the potential role of BnaC4.BOR1;1C in this process using RNAi lines. Seedlings grown in ${ }^{11} \mathrm{~B}$-enriched solution $(100 \mu \mathrm{M})$ were transferred to 0 $\mu \mathrm{M} B$ for two days. $B$ concentration was reduced in the new leaves and old leaves (Fig. 6b). No obvious reduction was observed in other tissues. The distribution ratio of $B$ in new leaves was increased after $B$ starvation, while it was decreased in old leaves (Fig. 6c). No big changes were detected for other tissues. Although a small amount of B was transported into new leaves from other tissues, the distribution pattern among wild-type plants and RNAi lines was similar, suggesting that BnaC4.BOR1;1C did not contribute to this process. To clarify whether BnaC4.BOR1;1c is involved in preferential $B$ translocation into new leaves; we performed the transient $B$ uptake assay of $B$. napus seedlings. To avoid the $B$ transport activity of BnaC4.BOR1;1 $\mathrm{C}$ in roots, chimera B. napus plants were generated (Fig. 6d) by grafting the wild type and RNAi scions on the wild-type rootstocks (named graft ${ }^{W T}$ and graft ${ }^{\mathrm{Ri}}$ ). Chimera plant grown in the ${ }^{11} \mathrm{~B}-$ enriched solution was transferred to $0.1 \mu \mathrm{M}{ }^{11} \mathrm{~B}$-enriched medium for one day followed by two days exposure in $1 \mu \mathrm{M}^{10} \mathrm{~B}$. The ${ }^{10} \mathrm{~B}$ concentrations in young leaves (L1) of graft ${ }^{\mathrm{Ri}}$ was lower than that in graft ${ }^{\mathrm{WT}}$ (Fig. 6e). In contrast, ${ }^{10} \mathrm{~B}$ concentration in hypocotyls of graft ${ }^{\mathrm{Ri}}$ was higher than that in grafts ${ }^{\mathrm{WT}}$ 
(Fig. 6e). In parallel, the distribution ratio of $B$ was lower for graft ${ }^{\mathrm{Ri}}$ young leaves (L1) and higher for graft $^{\mathrm{Ri}}$ stems and hypocotyls relative to that of graft ${ }^{\mathrm{WT}}$ (Fig. 6f). These results demonstrate that BnaC4.BOR1;1 c facilitates the preferential distribution of $B$ into developing tissues such as buds and leaves.

\section{Discussion}

Increasing studies had reported that vascular localization of various transporters in the shoots play an essential role in their substrate's mobility, such as NIP6;1 for the B acquisition of young leaves in Arabidopsis (Tanaka et al., 2008) and OsNIP3;1 for the B distribution into leaves in rice (Shao et al., 2017).

\section{BnaC4.BOR1;1c is regulated in response to $B$ availability mediated by $5^{\prime}-\mathrm{UTR}$}

B homeostasis is essential for the optimal growth of the plant through fine-tuning $B$ transporter expression. In China, a large agricultural soil area of usually possesses low B concentrations, which cannot satisfy the growing demand of B. napus (Xu et al., 2001). BnaC4.BOR1;1C was up-regulated by low B in the root, shoot, and flower of B. napus 'QY10' (Sun et al., 2012), and its expression level increased gradually within $24 \mathrm{~h}$ of low $B$ treatment (Chen et al., 2018). Low B inducible expression of BnaC4.BOR1;1c probably contributes to the B efficiency in 'QY10'. However, the low sensitivity of BnaC4.BOR1;1 1 to low B stress was reported in a European winter-type B. napus cv. Darmor-PBY018 (Diehn et al., 2019). Therefore, different B. napus $c v$. might have distinct $B$ response of BnaC4.BOR1;1c.

In this study, we demonstrate that the 5 ' terminal 29 nt in the 5'-UTR of BnaC4.BOR1;1c of 'QY10' mediates the B response (Fig. 1 and Fig. 2). In Arabidopsis, the transcription level of AtNIP5;1 was downregulated by high B (Takano et al., 2006), and the 5'-UTR of AtNIP5;1 is required for B-dependent mRNA degradation (Tanaka et al., 2011). Furthermore, the 'AUGUAA' cis-element in the 5'-UTR and its upstream conserved sequence 'UAUA' were found to induce ribosome stalling and mRNA degradation under high $B$ conditions (Tanaka et al., 2016). Interestingly, the $29 \mathrm{nt}$ in the 5'-UTR of BnaC4.BOR1;1c includes a mini UORF (AUGUAA) and, in particular, a sequence consensus 'CAUA' at the same position (Figure S1) corresponding to the 'UAUA' in 5'-UTR of AtNIP5;1. These results suggest that a common mechanism of B-dependent mRNA regulation might exist in both AtNIP5;1 and BnaC4.BOR1;1C in 'QY10'. However, the high B response of AtNIP5;1 is stronger (Takano et al., 2006) than that of BnaC4.BOR1;1C, probably due to the sequence inconsistency between them. 'ZS11' is a conventional commercial cultivar with high $B$ efficiency in China (Hua et al., 2016). We compared their 5'-UTR sequences of BnaC4.BOR1;1c (Figure S5) and found significant differences existed in the region between uORF1 and uORF2. Most importantly, mRNA degradation associated upstream conserved sequence before uORF ('UAUA' in AtNIP5; 1 and 'CAUA' in 'QY10' BnaC4.BOR1;1C) was '-ACA' in 'ZS11' (Figure S5). This result implies that BnaC4.BOR1;1C might have different $B$ responses among $B$. napus lines 
On the other hand, AtBOR1 showed two B-dependent regulatory mechanisms, in which high B rapidly triggers BOR1 protein endocytosis from PM for degradation in the vacuole (Takano et al., 2005, 2010; Kasai et al., 2011), and continuous toxic B supply induces translational suppression in the 5'-UTR (Aibara et al., 2018). The high B-dependent translational suppression in the 5'-UTR of AtBOR 1 was mediated by the multiple uORFs (Aibara et al., 2018). B-dependent regulation of AtNIP5;1 together AtBOR1 cooperatively maintain B homeostasis. We found a total of 5 uORFs in the 5'-UTR of BnaC4.BOR1;1C (Figure S1). Despite the deletion of $29 \mathrm{nt}$ or $97 \mathrm{nt}$ abolished the high B effect on mRNA abundance, the protein level was reduced partially under high B treatment (Figure S2). One possibility is that high B inhibits protein translation efficiency through 5'-UTR of BnaC4.BOR1;1c. The sequences UORF3, UORF4 and UORF5 in 5'-UTR of BnaC4.BOR1;1 $c$ between 'QY10' and 'ZS11' possess high conservation (Figure $\mathrm{S} 5)$, suggesting $\mathrm{B}$-dependent protein translation regulation of BnaC4.BOR1;1 gene is generalized for $B$. napus. Together, these results revealed a combined regulatory action of mRNA abundance and translation efficiency mediated by the 5'-UTR of 'QY10' BnaC4.BOR1;1C in response to B availability.

\section{BnaC4.BOR1;1c is responsible for B loading in roots and preferential distribution of B to developing tissues in shoots}

It is conceivable that BnaC4.BOR1;1 c may have common characteristics as AtBOR1 because of the high similarity of protein sequences such as polar localization of BnaC4.BOR1;1c on the PM of root cells toward the stele-side (Fig. 4). This polar localization presumably contributes to efficient B loading into the xylem in roots.

In Arabidopsis, polar localization of AtBOR1 localizes on the PM of epidermis and endodermis toward the stele-side in roots was proposed to efficiently load B into xylem for translocation (Takano et al., 2008). The $B$ transport activity assays of BnaC4.BOR1;1 in yeast and $B$. napus directly support that BnaC4.BOR1;1C is responsible for B loading in the root (Fig. 5).

Developing tissue in the shoot has low or no transpiration capability; thus the mineral elements demand is proposed to be facilitated preferentially by various transporters. The connection sites such as node and base of floral organ linking developing tissues and stem are important hubs for the nutrient's distribution (Yamaji and Ma, 2014). In Arabidopsis, AtBOR1 contributes to the preferential translocation of $\mathrm{B}$ to young leaves, while it is unclear that whether AtBOR1 functions at such hubs (Takano et al., 2001) because no evidence of AtBOR1 in nodes was documented. The xylem-to-phloem transfer of $B$ is mediated by the AtNIP6;1 in Arabidopsis (Tanaka et al., 2008) and by the OsNIP3;1 in rice (Shao et al., 2017) under low B conditions since their specific localization in the vascular cells. Most recently, rice OsBOR1 was found to be polarly localized in bundle sheath cells of nodes and xylem parenchyma cells of the leaf sheath, and it plays a vital role in distributing $B$ to new leaves and panicles (Shao et al., 2021). In this study, we found that BnaC4.BOR1;1 $\mathrm{C}$ is localized in the vascular xylem and cambium cells region in the nodes of developing tissues (Fig. 3), distinct from the AtBOR1 localization in the shoot (Yoshinari et al., 2016), implying the different roles between AtBOR1 and BnaC4.BOR1;1c. The biomass of $B$. napus is far more than the biomass of Arabidopsis; thus the efficient $\mathrm{B}$ acquisition is necessary to sustain optimal growth. 
There is little doubt that the vascular localization of BnaC4.BOR1;1 c might contribute to B re-distribution or distribution in shoot tissues. B is usually immobile in most plant species (Brown and Shelp, 1997). Based on our experiments, BnaC4.BOR1;1c did not contribute to the B re-distribution in shoots (Fig. 6b, C), although a small proportion B was redistributed into young leaves (Fig. $6 \mathrm{C}$ ) when plants were transferred from adequate $B$ condition to $B$ starvation condition, probably due to free $B$ in plants. The tracer analyses of B uptake in B. napus buds (Fig. 6a) and in grafted plants (Fig. 6d-f) demonstrated that BnaC4.BOR1;1c is important for the preferential distribution of $B$ in developing tissues. These results suggest that BOR1 protein plays a similar role in $B$. napus and rice. Furthermore, we observed the polar localization of BnaBOR1s, including BnaC4.BOR1;1c on the PM of cambium cells toward phloem (Fig. 4e-h). A reasonable answer to this is that polar localization of BnaBOR1s in cambium cells is beneficial to $B$ translocation from the xylem into the phloem. Taken together, the present data reveal that BnaC4.BOR1;1c is responsible for B loading in root and preferential distribution of B to developing tissues.

\section{Materials And Methods}

\section{Plant materials and growth conditions}

B-efficient B. napus 'QY10' (winter-type B. napus in China), the RNAi lines of BnaC4.BOR1;1C (Zhang et al., 2017), transgenic Arabidopsis (Col-0 background) were used in this study. For the pot growth of $B$. napus, seeds were sown in the soil, which includes $0.85 \mathrm{~g} \mathrm{NH}_{4} \mathrm{NO}_{3} \mathrm{~kg}^{-1}, 383.3 \mathrm{mg} \mathrm{KH}_{2} \mathrm{PO}_{4} \cdot 2 \mathrm{H}_{2} \mathrm{O} \mathrm{kg}^{-1}, 250 \mathrm{mg}$ $\mathrm{MgSO}_{4} \cdot 7 \mathrm{H}_{2} \mathrm{O} \mathrm{kg}^{-1}, 751.1 \mathrm{mg} \mathrm{KCl} \mathrm{kg}{ }^{-1}$. Pots were irrigated with $1,500 \mathrm{ml}$ ultrapure water supplemented with micronutrients $\left(3.5 \mathrm{mg}{ }^{11} \mathrm{~B}, 12.60 \mathrm{mg} \mathrm{MnCl} \cdot 4 \mathrm{H}_{2} \mathrm{O}, 1.54 \mathrm{mg} \mathrm{ZnSO}_{4} \cdot 7 \mathrm{H}_{2} \mathrm{O}, 0.56 \mathrm{mg} \mathrm{CuSO}_{4} \cdot 5 \mathrm{H}_{2} \mathrm{O}\right.$, $0.168 \mathrm{mg} \mathrm{Na} 2 \mathrm{MoO}_{4} \cdot 2 \mathrm{H}_{2} \mathrm{O}, 1.75 \mathrm{mmol}$ Fe-EDTA) to maintain proper humidity. For the inflorescence tracer $B$ experiment, the inflorescences with stem segments about $15 \mathrm{~cm}$ in length were cut and cultured two days in a hydroponic box with $5 \mu \mathrm{M}^{10} \mathrm{~B}$. For the hydroponic growth of $B$. napus, seeds were surfacesterilized. They germinated one week in ultrapure water and then were transferred into a quarter-strength solution for 5 days growth followed by 5 days half-strength solution treatment and full-strength solution culture. Modified Hoagland's solution was used in hydroponic growth (Li et al., 2019), in which $100 \mu \mathrm{M}$

${ }^{11} \mathrm{~B}$ was used. For the tracer $\mathrm{B}$ experiment of seedlings, seedlings of $B$. napus were washed with ultrapure water and then treated in $0.25 \mu \mathrm{M}^{11} \mathrm{~B}$ for 1 day followed by one-day growth in $5 \mu \mathrm{M}^{10} \mathrm{~B}$. For the Arabidopsis culture, a solid MGRL medium was prepared (Fujiwara et al., 1992) with $1 \%$ gellan gum and $1 \%$ sucrose. Transgenic Arabidopsis lines were established by the Agrobacterium-mediated in planta method (Clough and Bent, 1998). To generate chimera B. napus plants, a scion cut at $1-2 \mathrm{~cm}$ under cotyledon was inserted into a rootstock at the position $1 \mathrm{~cm}$ above the cotyledon. A silicon tube was used to support vertical growth. The grafted plants were placed in a transparent box with very high artificial humility. After one-week, grafted plants were successfully established.

\section{Plasmid construction}


To construct PrOBOR1;1c (5'-UTR): GUS and ProBOR1;1c ( $\Delta 5^{\prime}$-UTR): GUS, promoter sequences of BnaC4.BOR1;1c with or without 5'-UTR were amplified from 'QY10' DNA by PCR reaction with specific primers (Table S1), then fused with Scal and Smal digested PBI121 fragment using In-Fusion Cloning kits

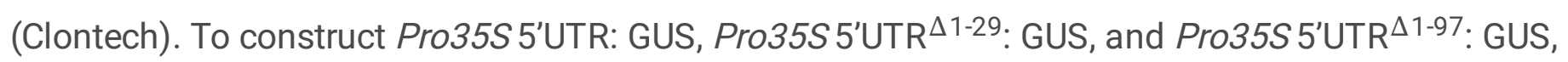
truncated 5' UTR sequences were amplified by PCR reaction with specific primers (Table S1) and were fused with Xbal digested PBI121using In-Fusion Cloning kits (Clontech). To generate Pro35S 5'UTR ${ }^{\Delta 1-29}$ : GUS, Pro35S 5'UTR: GUS was used as a template by PCR reaction using specific primers, and the PCR product was self-fused.

\section{Gene expression analysis}

To investigate GUS expression, 10-d-old Arabidopsis seedlings grown on $100 \mu \mathrm{M}$ B were transferred to $0.25 \mu \mathrm{M}$ B or $250 \mu \mathrm{M}$ B medium for $2 \mathrm{~d}$ growth. Plants were harvested for sampling. RNA was extracted using TRIZOL Reagent (Invitrogen, CA, USA). Reverse transcription was carried out using M-MLVReverse Transcriptase (Promega) according to the manufacturer's protocol. RT fluorescence quantitative PCR was performed using the SYBR Green Real-Time PCR Master Mix Kit (Toyobo, Japan) and the CFX96 ${ }^{\mathrm{TM}}$ RealTime PCR Detection System (Bio-Rad, Hercules, CA, USA). Actin and Tubulin were used as internal controls with primers F: 5'-ACAGTGTCTGGATCGGTGGTTC-3', R: 5'-TGCCTCATCATACTCAGCCTTG-3' (ACTIN); F: 5'-CAGCAATACAGTGCCTTGAGTG-3', R: 5'-CCTGTGTACCAATGAAGGAAAGCC-3' (TUBULIN). Each gene's relative expression level was calculated and normalized based on these two internal controls using the $\Delta \Delta$ Ct method (Livak \& Schmittgen 2001).

\section{$\beta$-Glucuronidase (GUS) histochemical staining and quantification of GUS activity}

$\beta$-Glucuronidase (GUS) histochemical staining of GUS reporter lines was performed using the GUS Histochemical Kit (bioshap, Cat. BL622A). The sample photos were taken using an Olympus SZX16 stereomicroscope. For the GUS activity assay, GUS line's total protein was extracted using the GUS extraction buffer (50 mM sodium phosphate buffer (pH 7.0), $10 \mathrm{mM} \beta$-mercaptoethanol, $1 \mathrm{mM} \mathrm{Na}_{2}-$ EDTA $2 \mathrm{H}_{2} \mathrm{O}$, and $0.1 \%$ Triton $\mathrm{X}-100$ ). After centrifugation at $12,000 \mathrm{rpm}$, the total protein concentration was determined by using the Bradford assay (Bradford, 1976). $50 \mu \mathrm{g}$ of total protein was mixed with 450 $\mu \mathrm{L}$ MUG buffer incubated at $37^{\circ} \mathrm{C} .40 \mu \mathrm{L}$ interaction solution was obtained at $5 \mathrm{~min}, 15,25$, or $35 \mathrm{~min}$, respectively, and mixed with $160 \mu \mathrm{L}$ of $0.2 \mathrm{M} \mathrm{Na}_{2} \mathrm{CO}_{3}$ to stop the interaction. GUS fluorescence (excitation: $365 \mathrm{~nm}$; emission: $455 \mathrm{~nm}$ ) was measured using a microplate reader (TECAN Infinite M200). The standard curve was established by mixing $40 \mu \mathrm{L}$ 4-MU (4-methylumbelliferone) and $160 \mu \mathrm{L} 0.2 \mathrm{M}$ $\mathrm{Na}_{2} \mathrm{CO}_{3}$, in which the $4-\mathrm{MU}$ was set as $1 / 2^{6} \mathrm{mM}, 1 / 2^{7} \mathrm{mM}$, until to $1 / 2^{12} \mathrm{mM}$ ).

\section{Immunohistological staining of BnaC4.BOR1;1c}

To perform in vivo immunohistological staining of BnaC4.BOR1;1 in B. napus, an antibody against BnaC4.BOR1;1C was obtained by purifying the rabbit antiserum, which was prepared through immunizing rabbits with an artificial peptide (SSTPLNNRSLSSPR). The immunohistological staining method (Ma et 
al., 2007) was used with modification. Briefly, B. napus seedlings (20-d-old), precultured in $25 \mu \mathrm{M} B$, were transferred to $0.25 \mu \mathrm{M}$ B or $250 \mu \mathrm{M}$ B for $2 \mathrm{~d}$ growth. The roots, basal node, and nodes (petiole junction) from 'QY10' and RNAi plants were cut as 0.5-1 cm thickness and fixed in the solution at $4{ }^{\circ} \mathrm{C}(4 \%$ paraformaldehyde, $60 \mathrm{mM}$ sucrose, and $50 \mathrm{mM}$ Cacodylic acid). The samples were centrifuged at 7,000 rpm for $2 \mathrm{~min}$. After exposed to room temperature for $2 \mathrm{~h}$, samples were washed several times using $1 \mathrm{x}$ PBS buffer, then embedded by $5 \%$ agar (Nakalai, Tesque, Kyoto, Japan) for solid at $4^{\circ} \mathrm{C} .100 \mu \mathrm{m}$ specimens were prepared using a semi-automatic slicer and stored in 1XPBS buffer. Then the specimens were incubated in the $1 \mathrm{XPBS}$ buffer supplemented with $0.1 \%(\mathrm{w} / \mathrm{v})$ pectolyase $+0.3 \%(\mathrm{w} / \mathrm{v})$ Triton $\mathrm{X}-100$ for $2 \mathrm{~h}$. After washed with $1 \mathrm{xPBS}$, the specimens were blocked in 5\% (w/v) BSA/PBS for $10 \mathrm{~min}$, followed incubated with primary antibody (anti-BnaC4.BOR1;1 c, rabbit, 1:1000 dilution) for overnight. After washed with 1xPBS buffer, the specimens were incubated in secondary antibody (Alexa fluor 488-conjugated Goat anti-rabbit lgG $(\mathrm{H}+\mathrm{L})$ AS053, 1:2000 dilution) for $2 \mathrm{~h}$ without light. The specimens were then washed 5 times in $1 \times$ PBS and mounted with an antifade polyvinylpyrrolidone mounting medium (Beyotime, Shanghai, China). Fluorescence imaging was examined in the Leica SP8 system (Leica, Mannheim, Germany). GFP was excited by $488 \mathrm{~nm}$, and the signal was collected from $505-545 \mathrm{~nm}$ wavelength.

\section{In situ PCR}

The in situ PCR method (Athman et al., 2014) was used with modification. Briefly, fresh plant tissues were fixed overnight in FAA solution (63\% ethanol, $5 \%$ acetic acid, and $2 \%$ formalin) without vacuum infiltration step. After three times washes by buffer ( $63 \%$ ethanol and $5 \%$ acetic acid) and one-time wash by $1 \times$ PBS buffer, the samples were embedded in $5 \%$ agar (Nakalai, Tesque, Kyoto, Japan) for solid at $4{ }^{\circ} \mathrm{C} .75 \mu \mathrm{m}$ specimens were prepared using a semi-automatic slicer and stored in DEPC water containing $100 \mathrm{U}$ RNaseOUT (Takara Bio, Japan), 2.5\% DNase I (Promega, China) followed by 45 min incubation at $37^{\circ} \mathrm{C}$. Then $15 \mathrm{mM}$ EDTA was used to stop the reaction at $70^{\circ} \mathrm{C}$ for $15 \mathrm{~min}$. After wash by cold DEPC water, the reverse transcription (Promega, China) was performed in the RT mix with BnaC4.BOR1;1c specific primer $\left(4 \mu \mathrm{l} 5 \mathrm{X}\right.$ buffer, $2 \mu \mathrm{l} 10 \mathrm{mM}$ dNTPs, $1 \mu \mathrm{l} 0.1 \mathrm{M} \mathrm{DTT}, 10 \mu \mathrm{l} \mathrm{H}_{2} \mathrm{O}$ and $1 \mu \mathrm{l}$ reverse primer at $65^{\circ} \mathrm{C}$ for $5 \mathrm{~min}$.

Then $1 \mu \mathrm{l}$ M-MLVReverse Transcriptase and $1 \mu \mathrm{l}$ RNaseOUT were added into the tube on the ice, followed by $1 \mathrm{~h}$ incubation at $50^{\circ} \mathrm{C}$ and $5 \mathrm{~min}$ at $85^{\circ} \mathrm{C}$. The negative control was prepared as above without a specific primer. Specimens were transferred into tube containing PCR mix [5 $\mu 10 \times$ Taq buffer (Aidlab bio.), $1 \mu \mathrm{l} 10 \mathrm{mM}$ mixed dNTPs , $0.2 \mu \mathrm{l}$ digoxigenin-11-dUTP (Roche; $4 \mu \mathrm{M}$ ), $2.5 \mu \mathrm{l} 10 \mathrm{mM}$ forward primer, $2.5 \mu \mathrm{l} 10 \mathrm{mM}$ reverse primer, $1 \mu \mathrm{l} \mathrm{Taq} \mathrm{polymerase} \mathrm{(Aidlab} \mathrm{bio),} 38.3 \mu \mathrm{l} \mathrm{H}_{2} \mathrm{O}$ ]. After twice washes by $1 \mathrm{x}$ PBS, specimens were blocked $30 \mathrm{~min}$ in $1 \mathrm{x}$ block solution at room temperature $(10 \mathrm{mg} \mathrm{BSA}$ in $10 \mathrm{ml} 1 \mathrm{x}$ PBS). 1.5 U AP-conjugated anti-DIG Fab fragments (Roche) were added for $1 \mathrm{~h}$ incubation at room temperature. The specimens were washed twice for 15 min using buffer $(0.1 \mathrm{M} \mathrm{Tris-Cl} ; 0.15 \mathrm{M} \mathrm{NaCl}, \mathrm{pH}$ 9.5) and then incubated in $50 \mu \mathrm{l} \mathrm{BM}$ purple (Roche) for $2 \mathrm{~h}$. Twice washes by washing buffer to remove the blue solution, the specimens were mounted on the microscope slide for imaging.

\section{Measurement of B concentration}


All samples were dried at $65^{\circ} \mathrm{C}$ in an oven for 3-4 $\mathrm{d}$ and then ground into fine powders using carnelian mortar. $1 \mathrm{M} \mathrm{HCl}$ was used to digest dry powders on the shaker for $2 \mathrm{~h}$ at $250 \mathrm{rpm}$. The solution was filtered, and B concentration was measured by inductively coupled plasma mass spectrometer (ELAN DRC-e; Perkin Elmer, USA).

\section{Statistical Analysis of Data}

Data were analyzed using Student's $t$-test and Duncan's test. Significance was defined when P value $<$ 0.05 .

\section{Declarations}

\section{Acknowledgements}

This work was funded by the National Key Research and Development Program of China (Grant no. 2016YFD0100700), National Natural Science Foundation of China (Grant no. 31772380), the Fundamental Research Funds for the Central Universities of China (Grant No. 2662019PY058, 2662019PY013), and Natural Science Foundation of Hubei Province (2019CFB467). We thank Dr. Limei Zhang and Xiangsheng Ye (Huazhong Agricultural University, China) for the technical assistance.

\section{Conflict of interest}

The authors declare no competing financial interests.

\section{Author contributions}

F.X. and S.W designed the research; S.W, L.L, D.Z, Y.H and Z.Z performed the experiments and analyzed the data; S.W. wrote the manuscript; all authors read and approved it.

\section{References}

1. Aibara I, Hirai T, Kasai K, Takano J, Onouchi H, Naito S, Fujiwara T, Miwa, K (2018)Boron-dependent translational suppression of the borate exporter BOR1 contributes to the avoidance of boron toxicity. Plant Physiol 177:759-774

2. Athman A, Tanz SK, Conn VM, Jordans C, Mayo GM, Ng WW, Burton RA, Conn SJ, Gilliham M (2014) Protocol: A fast and simple in situ PCR method for localising gene expression in plant tissue. Plant Methods 10:29

3. Bradford MM (1976) A rapid and sensitive method for the quantitation of microgram quantities of protein utilizing the principle of protein-dye binding. Anal Biochem 72:248-254

4. Broadley M, Brown P, Cakmak I, Rengel Z, Zhao F (2012) Function of Nutrients: Micronutrients. In: Marschner's Mineral Nutrition of Higher Plants, 3rd edn. Academic Press, San Diego, pp 191-248

5. Brown PH, Shelp BJ (1997) Boron mobility in plants. Plant Soil 193:85-101 
6. Chatterjee M, Tabi Z, Galli M, Malcomber S, Buck A, Muszynski M, Gallavotti A (2014) The boron efflux transporter ROTTEN EAR is required for maize inflorescence development and fertility. Plant Cell 26:1-17

7. Chen H, Zhang Q, He M, Wang S, Shi L, Xu F (2018) Molecular characterization of the genome-wide BOR transporter gene family and genetic analysis of BnaC04.BOR1;1c in Brassica napus. BMC Plant Biol 18:1-14

8. Clough SJ, Bent AF (1998) Floral dip: a simplified method for Agrobacterium-mediated transformation of Arabidopsis thaliana. Plant J 16:735-743

9. Diehn T A, Bienert M D, Pommerrenig B, Liu Z, Spitzer C, Bernhardt N, Fuge J, Bieber A, Richet N, Chaumont F, Bienert G P. (2019). Boron demanding tissues of Brassica napus express specific sets of functional Nodulin26-like Intrinsic Proteins and BOR1 transporters. Plant J 100: 68-82

10. Durbak AR, Phillips KA, Pike S, O'Neill MA, Mares J, Gallavotti A, Malcomber ST, Gassmann W, McSteen $P$ (2014) Transport of boron by the tassel-less 1 aquaporin is critical for vegetative and reproductive development in maize. Plant Cell 26:2978-2995

11. Fujiwara T, Hirai MY, Chino M, Komeda Y, Naito S (1992) Effects of sulfur nutrition on expression of the soybean seed storage protein genes in transgenic petunia. Plant Physiol 99:263-268

12. Funakawa H, Miwa K (2015) Synthesis of borate cross-linked rhamnogalacturonan II. Front Plant Sci $6: 223$

13. Hanaoka H, Uraguchi S, Takan J, Tanaka M, Fujiwara T (2014) OsNIP3;1, a rice boric acid channel, regulates boron distribution and is essential for growth under boron-deficient conditions. Plant $\mathrm{J}$ 78:890-902

14. Hua Y, Zhang D, Zhou T, He M, Ding G, Shi L, Xu F (2016) Transcriptomics-assisted quantitative trait locus fine mapping for the rapid identification of a nodulin 26-like intrinsic protein gene regulating boron efficiency in allotetraploid rapeseed. Plant, Cell Environ. 39: 1601-1618

15. Huang L, Bell RW, Dell B (2001) Boron supply into wheat (Triticum aestivum L. cv. Wilgoyne) ears whilst still enclosed within leaf sheaths. J Exp Bot 52:1731-1738

16. Kasai K, Takano J, Miwa K, Toyoda A, Fujiwara T (2011) High boron-induced ubiquitination regulates vacuolar sorting of the BOR1 borate transporter in Arabidopsis thaliana. J Biol Chem 286:61756183

17. Leaungthitikanchana S, Fujibe T, Tanaka M, Wang S, Sotta N, Takano J, Fujiwara T (2013)Differential expression of three BOR1 genes corresponding to different genomes in response to boron conditions in hexaploid wheat (Triticum aestivum L.). Plant Cell Physiol 54:1056-1063

18. Leonard A, Holloway B, Guo M, Rupe M, Yu G, Beatty M, Zastrow-Hayes G, Meeley R, Llaca V, Butler K et al (2014) tassel-less 1 encodes a boron channel protein required for inflorescence development in maize. Plant Cell Physiol 55:1044-1054

19. Livak KJ, Schmittgen TD (2001) Analysis of relative gene expression data using real-time quantitative PCR and the 2- $\Delta \Delta C T$ method. Methods 25:402-408 
20. Li T, Choi W-G, Wallace IS, Baudry J, Roberts DM (2011) Arabidopsis thaliana NIP7;1: an antherspecific boric acid transporter of the aquaporin superfamily regulated by an unusual tyrosine in helix 2 of the transport pore. Biochemistry 50:6633-6641

21. Li Y, Wang X, Zhang H, Wang S, Ye X, Shi L, Xu F, Ding G (2019) Molecular identification of the phosphate transporter family 1 (PHT1) genes and their expression profiles in response to phosphorus deprivation and other abiotic stresses in Brassica napus. PLoS One 14:1-23

22. Ma JF, Yamaji N, Mitani N, Tamai K, Konishi S, Fujiwara T, Katsuhara M, Yano M (2007) An efflux transporter of silicon in rice. Nature 448:209-212

23. Marentes E, Shelp BJ, Vanderpool RA, Spiers GA (1997) Retranslocation of boron in broccoli and lupin during early reproductive growth. Physiol Plant 100:389-399

24. Matoh T, Ochiai K (2005) Distribution and partitioning of newly taken-up boron in sunflower. Plant Soil 278:351-360

25. Miwa K, Takano J, Omori H, Seki M, Shinozaki K, Fujiwara T (2007) Plants tolerant of high boron levels. Science 318:1417

26. Nable RO, Bañuelos GS, Paull JG (1997) Boron toxicity. Plant Soil 193:181-198

27. O'Neill MA (2001) Requirement of borate cross-linking of cell wall rhamnogalacturonan II for arabidopsis growth. Science 294:846-849

28. Nakagawa Y, Hanaoka H, Kobayashi M, Miyoshi K, Miwa K, Fujiwara T (2007) Cell-type specificity of the expression of OS BOR1, a rice efflux boron transporter gene, is regulated in response to boron availability for efficient boron uptake and xylem loading. Plant Cell 19:2624-2635

29. Reid R (2007) Identification of boron transporter genes likely to be responsible for tolerance to boron toxicity in wheat and barley. Plant cell Physiol 48:1673-1678

30. Routray P, Li T, Yamasaki A, Yoshinari A, Takano J, Choi WG, Sams CE, Roberts DM (2018) Nodulin intrinsic protein $7 ; 1$ is a tapetal boric acid channel involved in pollen cell wall formation. Plant Physiol 178:1269-1283

31. Schnurbusch T, Hayes J, Hrmova M, Baumann U, Ramesh SA, Tyerman SD, Langridge P, Sutton T (2010) Boron toxicity tolerance in barley through reduced expression of the multifunctional aquaporin HvNIP2;1. Plant Physiol

32. Sun J, Shi L, Zhang C, Xu F (2012) Cloning and characterization of boron transporters in Brassica napus. Mol Biol Rep 39:1963-1973

33. Shao J, Yamaji N, Liu XW, Yokosho K, Shen RF, Ma JF (2018) Preferential distribution of boron to developing tissues is mediated by the intrinsic protein OsNIP3;1. Plant Physiol 176:1739-1750

34. Shao JF, Yamaji N, Huang S, Ma JF (2021) Fine regulation system for distribution of boron to different tissues in rice. New Phytol 230:656-668

35. Sutton T, Baumann U, Hayes J, Collins NC, Shi B-J, Schnurbusch T, Hay A, Mayo G, Pallotta M, Tester $\mathrm{M}$ et al (2007) Boron-toxicity tolerance in barley arising from efflux transporter amplification. Science 318:1446-1449 
36. Takano J, Miwa K, Fujiwara T (2008) Boron transport mechanisms: collaboration of channels and transporters. Trends Plant Sci 13:451-457

37. Takano J, Miwa K, Yuan L, von Wirén N, Fujiwara T (2005) Endocytosis and degradation of BOR1, a boron transporter of Arabidopsis thaliana, regulated by boron availability. Proc Natl Acad Sci U S A 102:12276-12281

38. Takano J, Noguchi K, Yasumori M, Kobayashi M, Gajdos Z, Miwa K, Hayashi H, Yoneyama T, Fujiwara T (2002) Arabidopsis boron transporter for xylem loading. Nature 420:337-340

39. Takano J, Tanaka M, Toyoda A, Miwa K, Kasai K, Fuji K, Onouchi H, Naito S, Fujiwara T (2010) Polar localization and degradation of Arabidopsis boron transporters through distinct trafficking pathways. Proc Natl Acad Sci U S A 107:5220-5225

40. Takano J, Wada M, Ludewig U, Schaaf G, von Wirén N, Fujiwara T (2006) The Arabidopsis major intrinsic protein NIP5; 1 is essential for efficient boron uptake and plant development under boron limitation. Plant Cell 18:1498-1509

41. Takano J, Yamagami M, Noguchi K, Hayashi H, Fujiwara T (2001) preferential translocation of boron to young leaves in Arabidopsis thaliana regulated by the BOR1 gene. Soil Sci Plant Nutr 47:345-357

42. Tanaka M, Sotta N, Yamazumi Y, Yamashita Y, Miwa K, Murota K, Chiba Y, Hirai MY, Akiyama T, Onouchi $\mathrm{H}$ et al (2016) The minimum open reading frame, AUG-stop, induces boron-dependent ribosome stalling and mRNA degradation. Plant Cell 28:2930-2849

43. Tanaka M, Wallace IS, Takano J, Roberts DM, Fujiwara T (2008) NIP6;1 is a boric acid channel for preferential transport of boron to growing shoot tissues in Arabidopsis. Plant Cell 20:2860-2875

44. Tanaka M, Takano J, Chiba Y, Lombardo F, Ogasawara Y, Onouchi H, Naito S, Fujiwara T (2011) Boron-dependent degradation of NIP5;1 mRNA for acclimation to excess boron conditions in Arabidopsis. Plant Cell 23:3547-3559

45. Warington $\mathrm{K}$ (1923) The effect of boric acid and borax on the broad bean and certain other plants. Ann Bot 37:629-672

46. Xu F, Wang Y, Meng J (2001) Mapping boron efficiency gene (s) in Brassica napus using RFLP and AFLP markers. Plant Breed 10:31-324

47. Yamaji N, Ma JF (2014) The node, a hub for mineral nutrient distribution in graminaceous plants. Trends Plant Sci 19:556-563

48. Yamaji N, Ma JF (2017) Node-controlled allocation of mineral elements in Poaceae. Curr Opin Plant Biol 39:18-24

49. Yoshinari A, Fujimoto M, Ueda T, Inada N, Naito S, Takano J (2016) DRP1-dependent endocytosis is essential for polar localization and boron-induced degradation of the borate transporter BOR1 in arabidopsis thaliana. Plant Cell Physiol 57:1985-2000

50. Zhang Q, Chen H, He M, Zhao Z, Cai H, Ding G, Shi L, Xu F (2017) The boron transporter BnaC4.BOR1;1 c is critical for inflorescence development and fertility under boron limitation in Brassica napus. Plant Cell Environ 40:1819-1833 
Figures

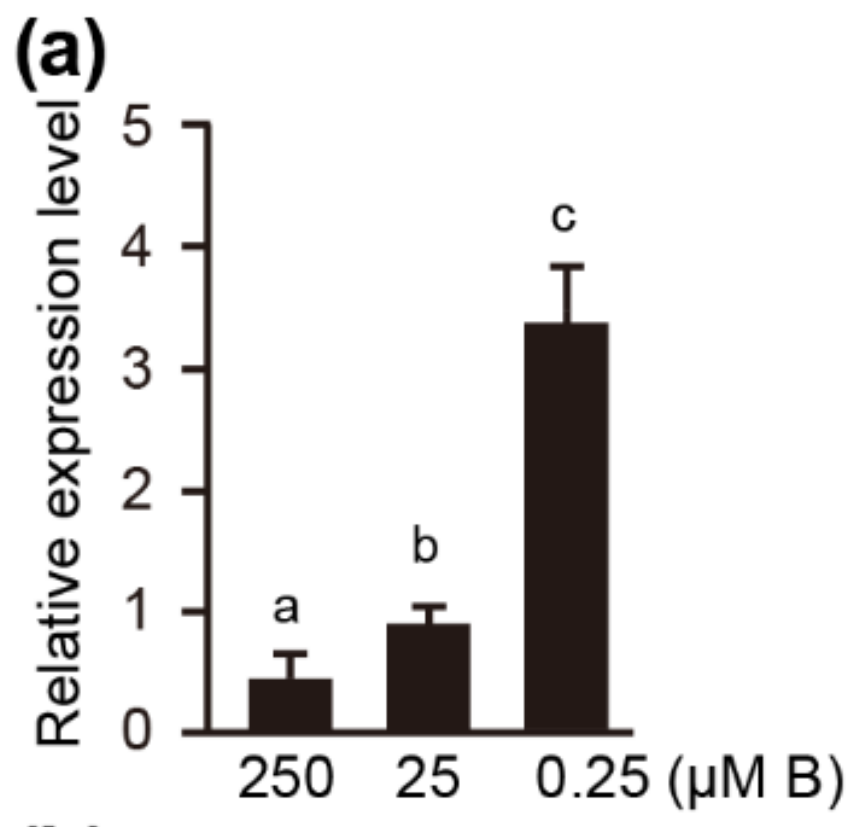

(b)

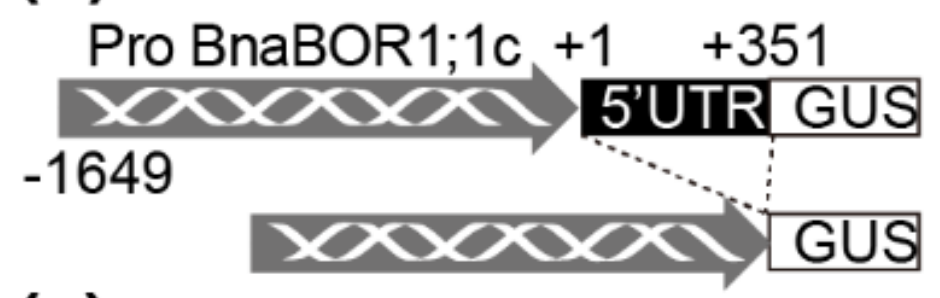

(c)

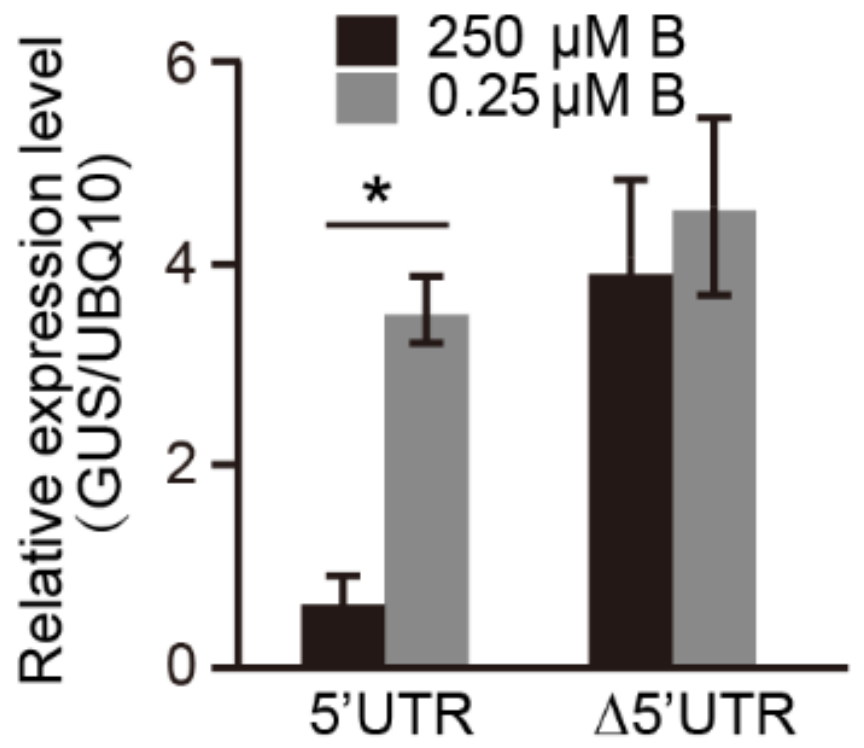

Figure 1

5'-UTR mediates high B response of BnaC4.BOR1;1c. (a) Relative expression levels of BnaC4.BOR1;1C gene in response to low $(0.25 \mu \mathrm{M} \mathrm{B})$, normal $(25 \mu \mathrm{M} \mathrm{B})$, and high $B(250 \mu \mathrm{M} \mathrm{B})$ treatments. Roots of 15day-old seedlings grown in hydroponic solution with different $B$ supply were used. Values represent 
means $\pm S D$ ( $n=3$ independent lines). Different letters indicate significantly different values (one-way ANOVA, Duncan's test). (b) Schematic representations of ProBnaC4.BOR1;1c (5'-UTR):GUS and ProBnaC4.BOR1;1c ( $\Delta 5^{\prime}$-UTR): GUS constructs. (c) Relative expression levels of these two constructs in the transgenic Arabidopsis lines responsed to B treatments (0.25 $\mu \mathrm{M} \mathrm{B}$ and $250 \mu \mathrm{M} \mathrm{B})$. 10-d-old Arabidopsis seedlings grown on $100 \mu \mathrm{M} \mathrm{B}$ medium were transferred to $0.25 \mu \mathrm{M}$ B or $250 \mu \mathrm{M} \mathrm{B}$ medium for $2 \mathrm{~d}$ growth. Experiments were performed using 3 independent homozygous lines. Values represent means $\pm \operatorname{SD}(n=3)$. ${ }^{*} p<0.05$, Student's t-test.
(a)
$+24$
$+92$
CUUUCAUGUAAUUCAA - - - - - -AUAACAUGUAAACUCG Mini uORF1 Mini uORF2

(b)

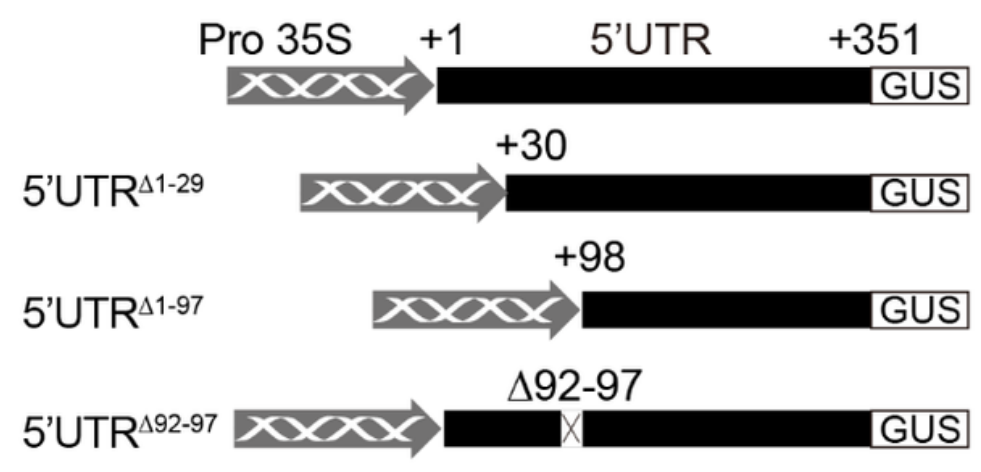

(c)

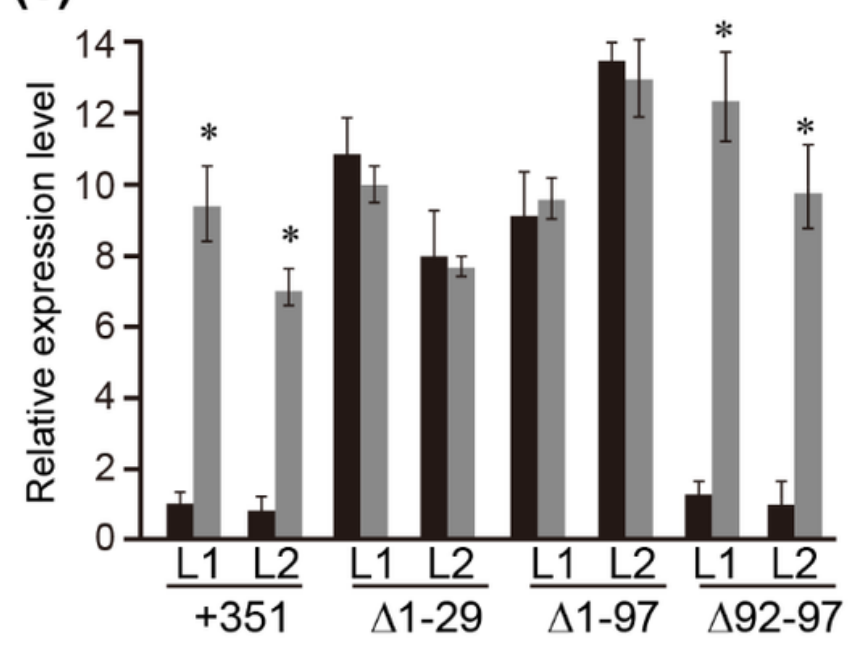

Figure 2

$5^{\prime}$ terminal region of $5^{\prime}-U T R$ is required for high $B$ response of BnaC4.BOR1;1c. (a) Sequences of two mini UORFs (AUGUAA) in 5'-UTR. (b-c) Truncation analyses of 5'-UTR for high B regulation of BnaC4.BOR1;1c. Truncated sequences with deletion of $29 \mathrm{nt}, 97 \mathrm{nt}$, and 92-97 nt in 5'-UTR were fused to 35S promoter to express GUS protein in transgenic Arabidopsis, respectively (b), and their relative expression levels in response to $B$ treatments were investigated (c). 10-d-old Arabidopsis seedlings grown on $100 \mu \mathrm{M} \mathrm{B}$ medium were transferred to $0.25 \mu \mathrm{M} \mathrm{B}$ or $250 \mu \mathrm{M} \mathrm{B}$ medium for $2 \mathrm{~d}$ growth. Values represent means $\pm \mathrm{SD}$ $(\mathrm{n}=3) .{ }^{*} \mathrm{p}<0.05$, Student's t-test. 


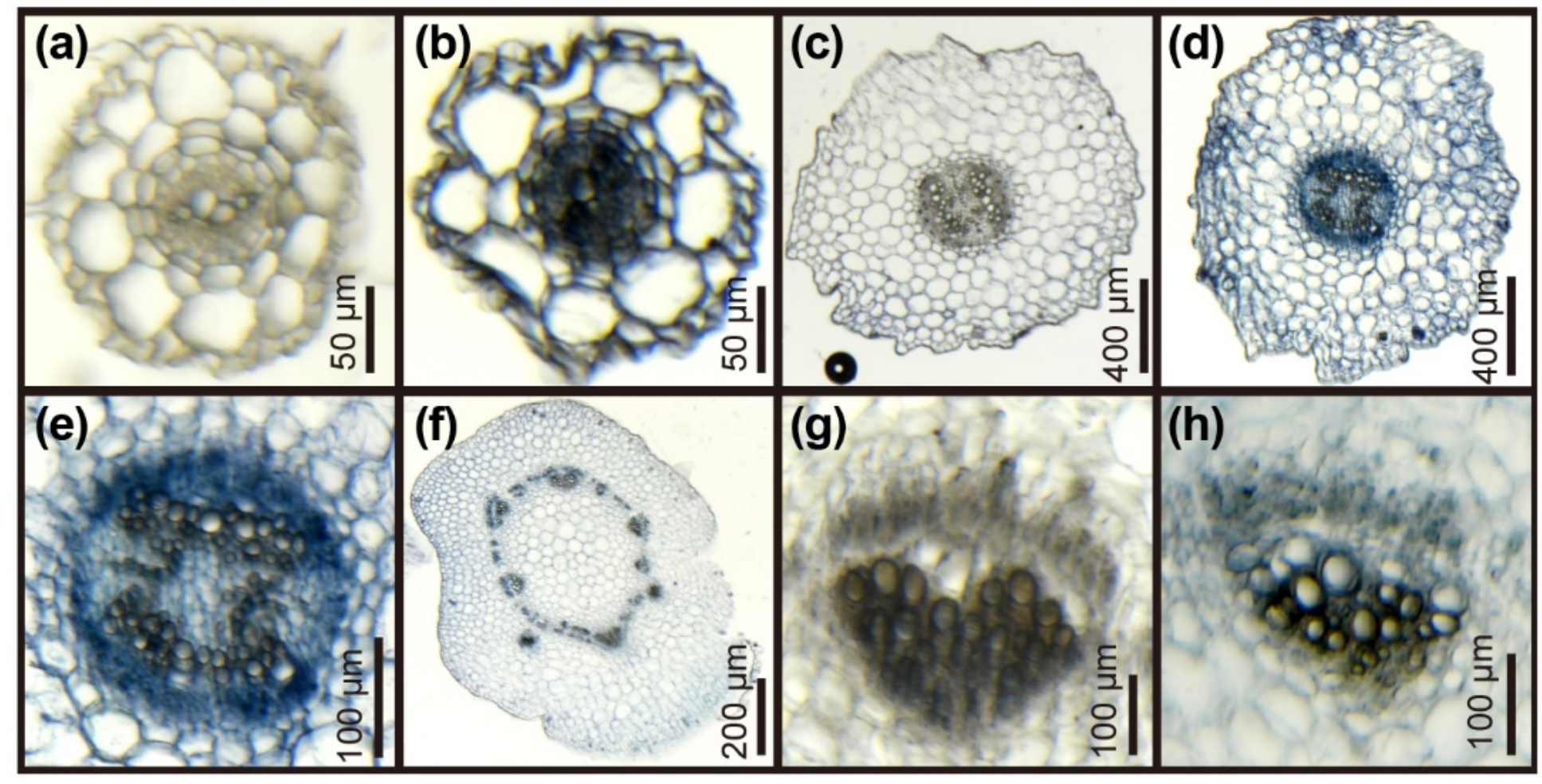

Figure 3

In situ PCR analysis of BnaC4.BOR1;1c in B.napus. In situ PCR analysis was performed in roots (a, b), hypocotyl (c-e), and node (f-h) of B. napus. Negative control in roots (a), hypocotyl (c), and node (g) was prepared due to the reverse transcription PCR without primer supply. 20-d-old B. napus seedlings grown on $25 \mu \mathrm{M} \mathrm{B}$ medium were transferred to $0.25 \mu \mathrm{M} \mathrm{B}$ medium for $2 \mathrm{~d}$ growth. Fresh plant tissues were cut and fixed in FAA solution for subsequent in situ PCR analysis. 


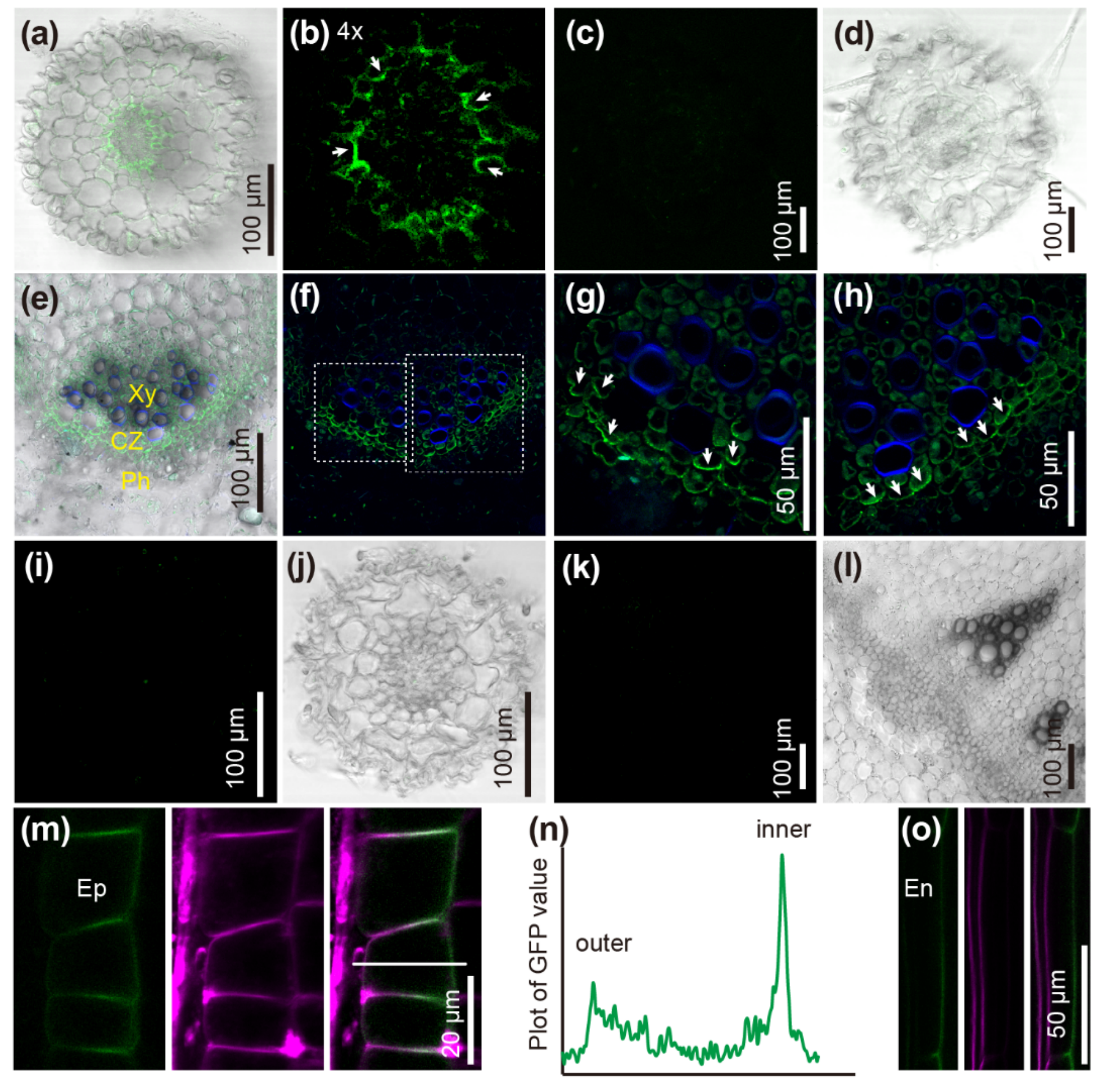

Figure 4

BnaC4.BOR1;1c localizes on the vascular cell layers of tissues. Immunohistological staining of BnaC4.BOR1;1c using specific anti-BnaC4.BOR1;1c antibody in roots and nodes. Roots $(a, b)$ and nodes $(e, f)$ of wild-type B. napus and roots of RNAi plant $(c, d)$ grown in $0.25 \mu \mathrm{M}$ B were used. (b) close-up view of $(a)$ and $(g, h)$ close-up view of (e) were shown. $250 \mu \mathrm{M} B$ treated wild-type roots $(i, j)$ and nodes $(k, l)$ were used to inhibit BnaBOR1s expression in B. napus. Xy, xylem; CZ, cambium; Ph, Phloem. Localization analysis of Arabidopsis expressing 35s: BnaC4.BOR1;1c-GFP in epidermis (m) and endodermis (o). FM4- 
64 (magenta) was used to stain the plasma membrane. The GFP signal intensity on the plasma membrane toward the soil-side (outer) and the stele-side (inner) was quantified by line plot (n). Ep, epidermis; En, endodermis.

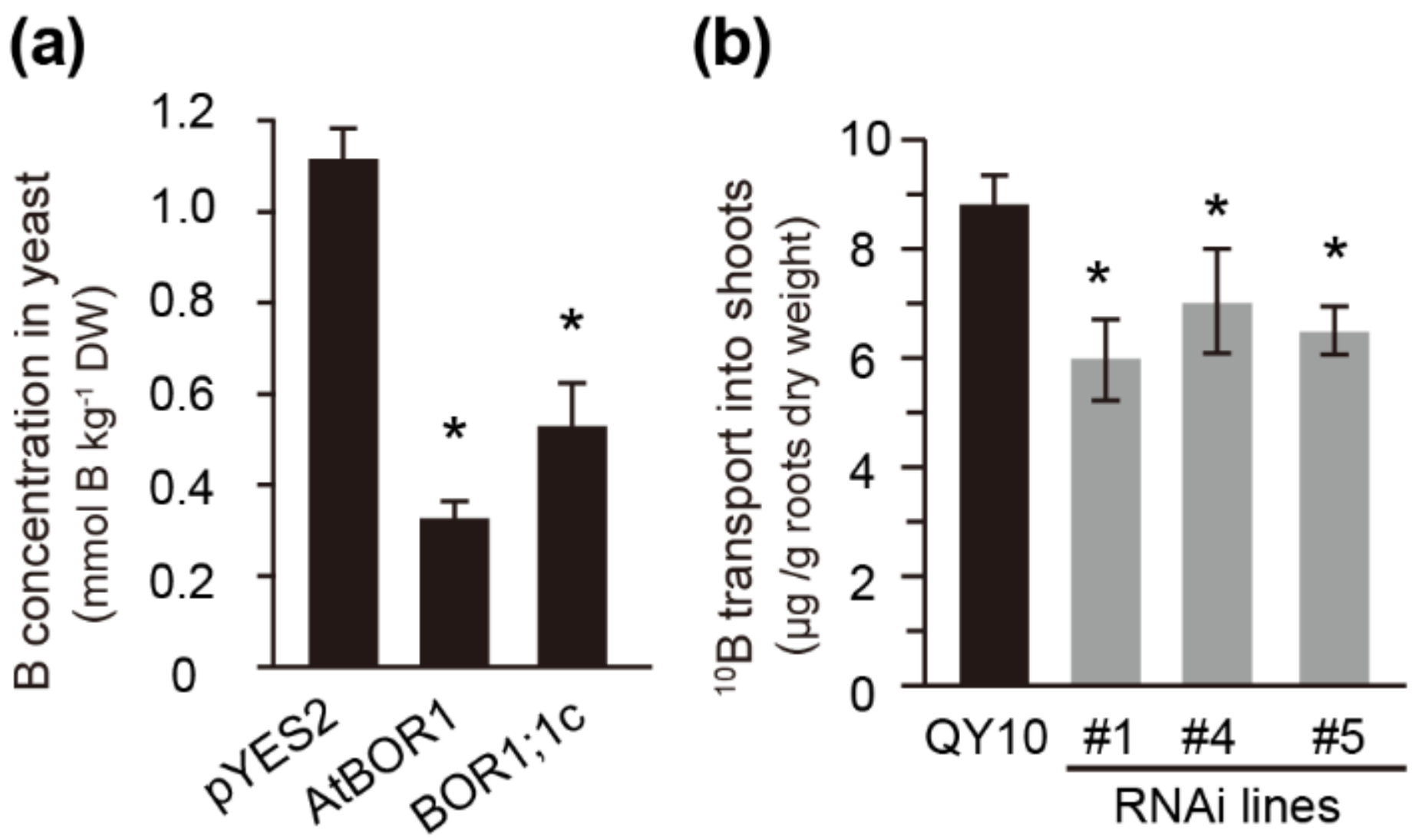

Figure 5

BnaC4.BOR1;1C transport B in yeast and B. napus. (a) Yeasts were incubated in $500 \mu \mathrm{M}$ B for 60 min in galactose medium. The $B$ intracellular concentrations in yeast expressing 3 vectors above were measured. Values represent means $\pm S D(n=3)$. (b) Comparison of transient B uptake in 'QY10' and BnaC4.BOR1;1c RNAi lines. 10-day-old seedlings grown on $100 \mu \mathrm{M}$ 11B enriched hydroponic solution was treated in $0.25 \mu \mathrm{M} 11 \mathrm{~B}$ for 1 day followed by 1-day growth in $5 \mu \mathrm{M}$ 10B-enriched hydroponic solution. Values represent means $\pm S D(n=3)$. 
(a)

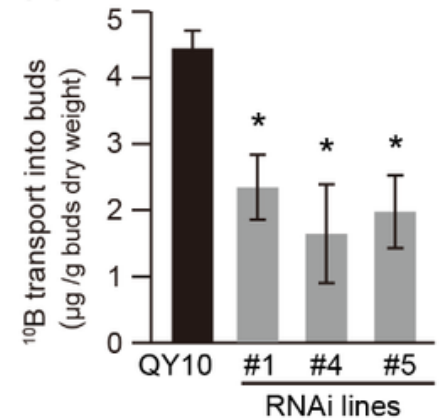

(b)

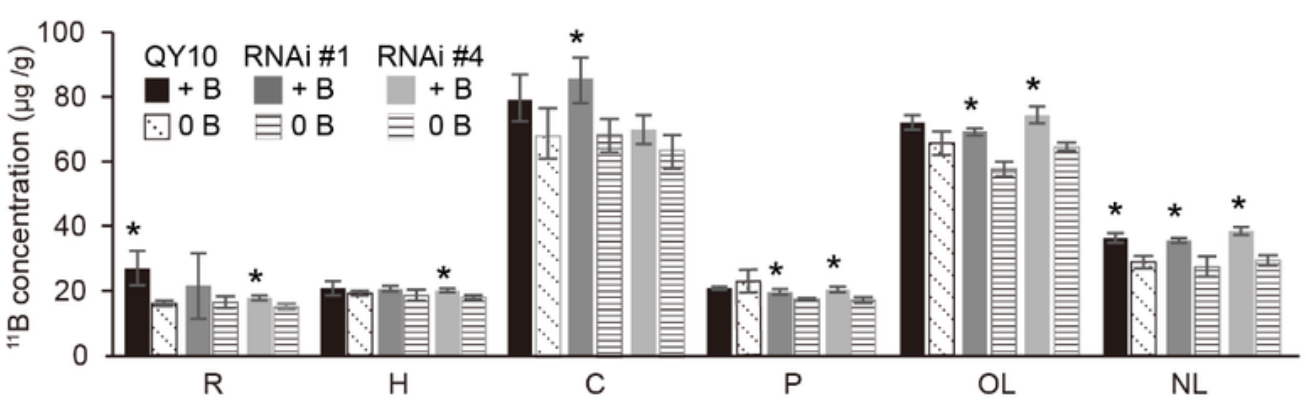

(c)

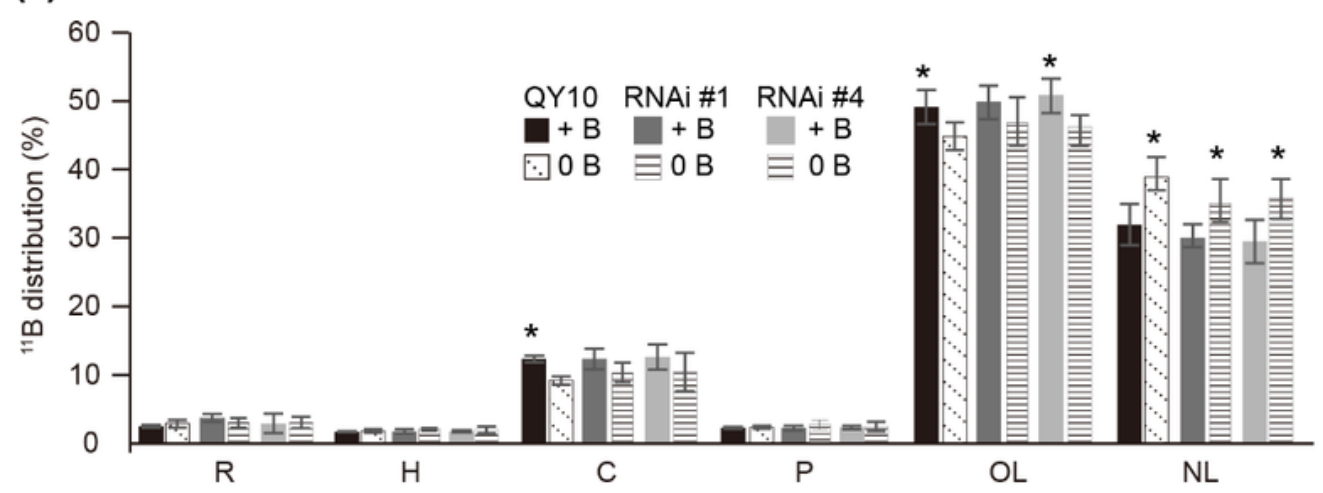

(d)

(e)
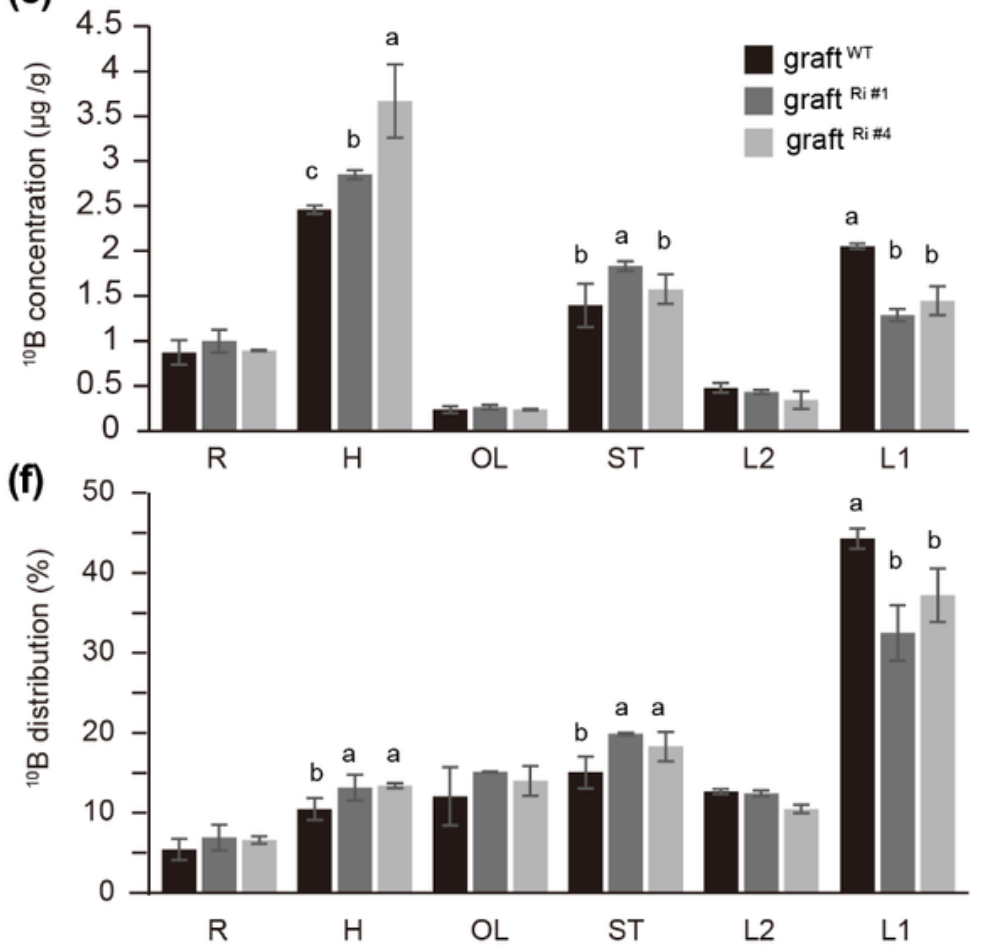

\section{Figure 6}

BnaC4.BOR1;1c preferentially transport B into developing tissues under B deficiency. (a) Comparison of transient B uptake in 'QY10'and BnaC4.BOR1;1c RNAi lines. Inflorescences cut from plants grown in a pot with $100 \mu \mathrm{M} 11 \mathrm{~B}$ irrigation were cultured 2 days in a hydroponic box with $5 \mu \mathrm{M} 10 \mathrm{~B}$. (b, c) Comparison of B centration and B distribution ratio in 'QY10' and BnaC4.BOR1;1c RNAi lines. 22-day-old seedlings (4 true leaves stage) grown on $100 \mu \mathrm{M} 11 \mathrm{~B}$-enriched hydroponic solution was treated with $\mathrm{B}$ deprivation for 2 
days. Tissues for $B$ concentration measurement were sampled before $B$ deprivation $(+B)$ and after $B$ deprivation ( 0 B). Significant differences between $+B$ and 0 B were statistically analyzed. Values represent means $\pm S D(n=3)$. * $p<0.05$, Student's t-test. (d) Chimera plants generation. Scions of $15-$ day-old 'QY10' and RNAi lines were inserted into 'QY10' rootstock to produce graftWT, graftRi\#1, and graftRi \#4. High humidity is required to maintain a high survival ratio. The leaves order was indicated in (d). (e-f) Comparison of transient B uptake and B distribution ratio in chimera plants. Chimera plants grown in $100 \mu \mathrm{M}$ 11B-enriched solution were transferred to $0.1 \mu \mathrm{M}$ 11B-enriched medium for 1 day followed by 2 days exposure in $1 \mu \mathrm{M}$ 10B-enriched solution. Tissues for $B$ concentration measurement were sampled before and after 10B treatment. Values represent means $\pm S D(n=3)$. Different letters indicate significantly different values (one-way ANOVA, Duncan's test). R: root; H: hypocotyl; C: cotyledon; P: petiole; OL: old leaves; NL: new leaves; ST: stem.

\section{Supplementary Files}

This is a list of supplementary files associated with this preprint. Click to download.

- FigureS.docx

- Primers.docx 